\title{
Evaluation of reliability of power distribution components: A case study of Sagamu Substation, Ogun State
}

\author{
Elijah Adebayo Olajuyin ${ }^{1, *}$ and Eniola Olubakinde ${ }^{2}$ \\ ${ }^{1}$ Electrical and Electronic Engineering Department, Bamidele Olumilua University of Education, Science and Technology, \\ Ikere Ekiti, Ekiti State, Nigeria. \\ ${ }^{2}$ Electrical and Electronics Engineering Department, Federal Polytechnic, Ile-oluji, Ondo State, Nigeria.
}

Global Journal of Engineering and Technology Advances, 2022, 10(01), 065-074

Publication history: Received on 01 December 2021; revised on 07 January 2022; accepted on 09 January 2022

Article DOI: https://doi.org/10.30574/gjeta.2022.10.1.0180

\begin{abstract}
Power system especially the distribution system which is the closest to the consumer is very fundamental and important to a nation's economy development and that was the reason this study titled "Evaluation of reliability of power system distribution components, a case study of Sagamu Substation, Ogun State" was carried out in response to the yawning of the consumer for reliable and stable power supply. It is indispensable to find means of shaping which component failure contributes most to the unavailability, outage or interruption of the distribution system, and how this unavailability essentially affects the customers. A year power outages data that caused as a result of failure on each of these components such as Switch gears, Supply lines (11Kv),Busbar, circuit breakers, Fuses, Switches, Outgoings feeders, Over current relays, Earth fault relays, Surge arresters, transformers e.t.c. were collected from Ibadan Electricity Distribution company (IBDEC), Sagamu Substation Zone, Ogun State and were typified in Table 1-11.The failure rate (f/yr) ( $\lambda$ ) of transformer, switch gear, supply line (incoming),bus bars, circuit breakers, fuses, switches, outgoing feeder, over current relay, earth fault relay and surge arrester were evaluated as follows $0.0059,0.0044,0.0011,0.6667,0.0007$, $0.0082,0.0000,0.0039,0.0003,0.0001$ and 0.0000 respectively and others such as average outages time (hours) ,outages time hours and other basic reliability indices were calculated and illustrated in Table 12. Some of these failures were also represented in bar chart. This method relates reliability theory with the experience gained from statistics and practical knowledge of components failures and maintenance. The findings from this work revealed that fuses had the highest failure followed by transformers and the least was surge arresters and it was also discovered that the outages time was reduced during the December period. This approach can be applied to rural and urban distribution systems. This submission made reliability theory a powerful tool to assist distribution Engineers in solving difficult and complicated problems.
\end{abstract}

Keywords: Evaluation; Power; Components; Reliability; Distribution; Outages

\section{Introduction}

Power systems are made up of three stages which are generation, transmission and distribution. The last stage which is distribution delivers energy to different consumers such as residential, commercials and industrials consumers'. Regular, effective and stable power supply is fundamental to the economy development of any nation. A country that is experiencing elliptic power supply will definitely lags behind in her socio-economic activities. The power sector in Nigeria has her peculiar problem like every other segments of the economy. The problem in power sector is pronounced in the sense that it will affect both the common man and the rich and it also required in every sector of the economy [1]. In most distribution substation in Nigeria, overhead lines feed the substation and it also delivers electricity to customers

\footnotetext{
${ }^{*}$ Corresponding author: Elijah Adebayo Olajuyin

Electrical and Electronic Engineering Department, Bamidele Olumilua University of Education, Science and Technology, Ikere Ekiti, Ekiti State, Nigeria.
} 
while few make use of underground cables. The insulation material used in overhead lines and in underground cables is the main difference. Overhead lines are insulated by air which is an external factor and makes lines exposed to different environmental factors such as animals, weather etc. One of the advantages of overhead lines is that it is not easily affected by high currents because the conductors are able to cope with temperatures higher than normal. That notwithstanding, the reliability of overhead lines is still greatly affected by high currents in many ways [2]. Lightning is a natural phenomenon which affects distribution substation system by directly striking the power contacts and sometimes indirectly by striking objects in close range which induces a travelling voltage wave. Usually, direct strikes are almost impossible to be protected against in a distribution system. Lightning surge arrestors are used to protect distribution system equipment from damage that might result as a result of induced high voltage caused by direct strikes. Furthermore, the body of the transformer which is solidly grounded and the neutral serves as lightning arrester ensuring protection against lightning in the distribution substation. Poles are structural elements needed to implement overhead distribution designs. They are conspicuous and can be easily tampered with by vehicular accident or wind. The safety of electrical wires on poles is the major reliability concern. When wind blows, it affects both the pole itself and the conductors. Laminated woods and cast concretes are the two types of pole majorly used and the wooden type is gaining popularity due to the fact that it is cheaper. In many cases, there are new attachments placed on existing poles which may mean that the pole may no longer meet wind loading criteria. Distribution poles are needed to be inspected and replaced when deterioration has occurred. A circuit breaker is also known as the automatically operated electrical switch that functions when a fault detected by interrupting the current flow. There are various sizes of circuit breaker which are from small devices up to large switchgear that used to protect low current circuit until high voltage circuit [3]. There are many types of circuit breakers. Switchgear is combinations of electrical disconnect switches, fuses or circuit breakers used to control, protect and isolate electrical equipment. Switches are safe to open under normal load current (some switches are not safe to operate under normal or abnormal conditions), while protective devices are safe to open under fault current. Very important equipment may have completely redundant and independent protective systems, while a minor branch distribution line may have very simple low-cost protection. Fuses are most used in power distribution networks are the fuses. This is due to its low cost when compared to other protection devices and its satisfactory operation for one of the major problems of the distribution networks that refer to the over current from short circuits by contact of the cables between each other, the vegetation or to the ground, and among others. As a fusetype protective device, it bases its operation on a metal link with specific characteristics of time versus current; when it reaches the maximum tolerable current, the heat melts the active element and releases the opening of circuit [4 Preventive maintenance measures will have effect on reliability of the system by prolonging the lifetime of an asset and improving the condition of an asset [5].Usually, preventive maintenance is the anticipation of failures and adoption of necessary preventive actions before they occur. The main objectives of preventive maintenance are to affect the work of inspection servicing and adjustment and to prevent failure of equipment during operation [6]. Reliability may also reduce the duration of power supply interruptions. Preventive maintenance activities could prevent the actual cause of the failure in the system. As a result, in cost- effective expenditure, Preventive maintenance should be employed where the reliability benefits outweigh the cost of implementing the Preventive maintenance [7]. Reliability of power system is the probability that a power system will meet the consumers' load requirements at any time [8]. Reliability of Power system can be explained as: The reliability of a System is the ability of the system to function satisfactorily under stated planned actions for a certain time frame [9] and [10]. The data collected from the selected substation is used to estimate the reliability of the components in the substation, the overall reliability of the substation and the customer reliability indices of the system.

The data collected from the selected substation is used to estimate the reliability of the components in the substation, the overall reliability of the substation and the customer reliability indices of the system.

\section{Collection of Data}

Power outages data recorded in the utility outage logbook were collected from the substation, the system here in Nigeria generally is too poor and lack intelligent devices that can alert or inform the distribution company whenever there is failure of any of the components or any form of interruption to the delivery of electricity to the customer. Outages due to scheduled maintenance and load shedding were not taken into consideration. This is so because scheduled outage or load shedding in the substation is intentional and cannot be attributed to any component failure which makes it hard for analysis to pin-point weak component if used. Data were collected from Sagamu distribution station for a period of a year with referencing to these components stated in the Table 1-11 below. 


\section{Reliability evaluation}

Reliability is the measure or the probability that a product or service will perform properly under normal operating condition for a specified period of time. It is used as a measure of the system's success in providing its function properly [10] and [11]. The failure rate $(f t)$ is calculated as

$\frac{n_{f}}{n_{O}}=\lambda(1)$

Where, $n_{f}$ is number of failures per year and $n_{O}$ is total numbers of observation per year and

Reliability is given as,

$R_{t}=e^{-\lambda t}(2)$

In reliability analysis, the arbitrary variable is the regularity time and so the usual function that is paramount suitable is the exponential distribution function due to the fact that it has only time as the independent variables [12]. Hence a constant hazard rate is often assumed and described the failure rate $(\lambda)$. When a constant failure rate is presupposed, the reliability functions now turn out to be [13].

$$
\begin{aligned}
& h(t)=\lambda \\
& F(t)=1-\ell^{-\lambda t} \\
& R(t)=1-F(t)=1-\ell^{-\lambda t} \\
& f(t)=\frac{d F(t)}{d t}=\lambda \ell^{-\lambda t}
\end{aligned}
$$

The above equations represented many fundamental reliability functions. Where:

$\mathrm{F}(\mathrm{t})$ is the failure distribution (this is the probability of finding a healthy component in a failed state after time $\mathrm{t}$ ).

$\mathrm{R}(t)$ is the reliability function. This is defined as the probability of finding a healthy component in a healthy state after time $t$.

$f(t)$ is the failure density distribution and which implies the rate at which a component fails at time $t$

$\mathrm{H}(\mathrm{t})$ is the Hazard rate is defined as the rate at which a component fails at time $\mathrm{t}$ given that it is healthy until time $\mathrm{t}$.

$\lambda=$ failure rate

$\mathrm{t}=$ time

- MTBF: Mean Time between Failures: This is the average time between two failures of the component. i.e.

$$
M T B F=\frac{\text { Total System operating hours }}{\text { Number of failures }}
$$

Availability $(A)=\frac{M T B R-M T T R}{M T B F}$

From these parameters, some other parameters can be derived (when assuming the negative exponential distribution)[14]. 
Table 1 Summary of Outage Frequency and Duration on Transformer

\begin{tabular}{|l|c|c|c|c|}
\hline Month & No. of Outages & Outage Time (Hours) & Total Hour & Failure Rate( $\boldsymbol{\lambda}$ ) \\
\hline January & 8 & 150 & 744 & 0.0108 \\
\hline February & 9 & 50 & 696 & 0.0115 \\
\hline March & 0 & 0 & 744 & 0.0000 \\
\hline April & 6 & 50 & 720 & 0.0083 \\
\hline May & 7 & 20 & 744 & 0.0094 \\
\hline June & 5 & 40 & 720 & 0.0070 \\
\hline July & 2 & 2 & 744 & 0.0027 \\
\hline August & 7 & 3 & 744 & 0.0094 \\
\hline September & 1 & 2 & 720 & 0.0014 \\
\hline October & 2 & 4 & 744 & 0.0027 \\
\hline November & 1 & 6 & 744 & 0.0013 \\
\hline December & 4 & 5 & 8784 & 0.0054 \\
\hline Total number of failures per year & 52 & 232 & & 720 \\
\hline
\end{tabular}

Table 2 Summary of Outage Frequency and Duration on Switchgear

\begin{tabular}{|l|c|c|c|c|}
\hline Month & No. of Outages & Outage Time (Hours) & Total Hour & Failure Rate( $\boldsymbol{\lambda}$ ) \\
\hline January & 12 & 24 & 744 & 0.0161 \\
\hline February & 14 & 18 & 696 & 0.0201 \\
\hline March & 5 & 15 & 744 & 0.0067 \\
\hline April & 0 & 0 & 720 & 0.0000 \\
\hline May & 5 & 3 & 744 & 0.0067 \\
\hline June & 0 & 0 & 720 & 0.0000 \\
\hline July & 0 & 0 & 744 & 0.0000 \\
\hline August & 0 & 0 & 744 & 0.0000 \\
\hline September & 0 & 0 & 720 & 0.0000 \\
\hline October & 0 & 0 & 744 & 0.0000 \\
\hline November & 1 & 3 & 720 & 0.0014 \\
\hline December & 2 & 4 & 744 & 0.0027 \\
\hline Total number of failures per year & 39 & 232 & 8784 & \\
\hline
\end{tabular}

Table 3 Summary of Outage Frequency and Duration on supply line (11KV)

\begin{tabular}{|l|c|c|c|c|}
\hline Month & No. of Outages & Outage Time (Hours) & Total Hour & Failure Rate( $\boldsymbol{\lambda}$ ) \\
\hline January & 1 & 10 & 744 & 0.0013 \\
\hline February & 3 & 5 & 696 & 0.0043 \\
\hline March & 1 & 2 & 744 & 0.0013 \\
\hline April & 5 & 4 & 720 & 0.0069 \\
\hline May & 0 & 0 & 744 & 0.0000 \\
\hline June & 0 & 0 & 720 & 0.0000 \\
\hline July & 0 & 0 & 744 & 0.0000 \\
\hline August & 0 & 0 & 744 & 0.0000 \\
\hline
\end{tabular}




\begin{tabular}{|l|c|c|c|c|}
\hline September & 0 & 0 & 720 & 0.0000 \\
\hline October & 0 & 0 & 744 & 0.0000 \\
\hline November & 0 & 0 & 720 & 0.0000 \\
\hline December & 0 & 0 & 744 & 0.0000 \\
\hline Total number of failures per year & 10 & 21 & 8784 & \\
\hline
\end{tabular}

Table 4 Summary of Outage Frequency and Duration on Busbar

\begin{tabular}{|l|c|c|c|c|}
\hline Month & No. of Outages & Outage Time (Hours) & Total Hours & Failure Rate $(\boldsymbol{\lambda})$ \\
\hline January & 0 & 0 & 744 & 0.0000 \\
\hline February & 0 & 0 & 696 & 0.0000 \\
\hline March & 0 & 0 & 744 & 0.0000 \\
\hline April & 1 & 5 & 720 & 0.0013 \\
\hline May & 1 & 4 & 744 & 0.0013 \\
\hline June & 1 & 3 & 720 & 0.0013 \\
\hline July & 0 & 0 & 744 & 0.0000 \\
\hline August & 2 & 6 & 744 & 0.0027 \\
\hline September & 3 & 8 & 720 & 0.0042 \\
\hline October & 0 & 0 & 744 & 0.0000 \\
\hline November & 0 & 0 & 720 & 0.0000 \\
\hline December & 0 & 0 & 744 & 0.0000 \\
\hline Total number of failures per year & 8 & 26 & & \\
\hline
\end{tabular}

Table 5 Summary of Outage Frequency and Duration on circuit breakers

\begin{tabular}{|l|c|c|c|c|}
\hline Month & No. of Outages & Outage Time (Hours) & Total Hours & Failure Rate $(\boldsymbol{\lambda})$ \\
\hline January & 0 & 3 & 744 & 0.0000 \\
\hline February & 1 & 5 & 696 & 0.0014 \\
\hline March & 1 & 4 & 744 & 0.0013 \\
\hline April & 0 & 0 & 720 & 0.0000 \\
\hline May & 0 & 0 & 744 & 0.0000 \\
\hline June & 0 & 0 & 720 & 0.0000 \\
\hline July & 2 & 5 & 744 & 0.0027 \\
\hline August & 1 & 5 & 744 & 0.0013 \\
\hline September & 0 & 7 & 720 & 0.0000 \\
\hline October & 0 & 0 & 744 & 0.0000 \\
\hline November & 0 & 0 & 720 & 0.0000 \\
\hline December & 1 & 7 & 744 & 0.0013 \\
\hline Total number of failures per year & 6 & 36 & 8784 & \\
\hline
\end{tabular}


Table 6 Summary of Outage Frequency and Duration on Fuses

\begin{tabular}{|l|c|c|c|c|}
\hline Month & No. of Outages & Outage Time (Hours) & Total Hours & Failure Rate( $\boldsymbol{\lambda}$ ) \\
\hline January & 5 & 7 & 744 & 0.0067 \\
\hline February & 7 & 6 & 696 & 0.0100 \\
\hline March & 9 & 5 & 744 & 0.0121 \\
\hline April & 6 & 4 & 720 & 0.0083 \\
\hline May & 3 & 2 & 744 & 0.0040 \\
\hline June & 6 & 8 & 720 & 0.0083 \\
\hline July & 2 & 7 & 744 & 0.0027 \\
\hline August & 7 & 5 & 720 & 0.0094 \\
\hline September & 7 & 3 & 744 & 0.0097 \\
\hline October & 6 & 5 & 720 & 0.0081 \\
\hline November & 9 & 7 & 744 & 0.0125 \\
\hline December & 5 & 6 & 8784 & 0.0067 \\
\hline Total number of failures per year & 72 & 65 & & 744 \\
\hline
\end{tabular}

Table 7 Summary of Outage Frequency and Duration on Switches

\begin{tabular}{|l|c|c|c|c|}
\hline Month & No. of Outages & Outage Time (Hours) & Total Hours & Failure Rate ( $\boldsymbol{\lambda}$ ) \\
\hline January & 0 & 0 & 744 & 0.0000 \\
\hline February & 0 & 0 & 696 & 0.0000 \\
\hline March & 1 & 5 & 744 & 0.0134 \\
\hline April & 2 & 5 & 720 & 0.0028 \\
\hline May & 0 & 0 & 744 & 0.0000 \\
\hline June & 0 & 0 & 720 & 0.0000 \\
\hline July & 0 & 0 & 744 & 0.0000 \\
\hline August & 0 & 0 & 744 & 0.0000 \\
\hline September & 0 & 0 & 720 & 0.0000 \\
\hline October & 0 & 0 & 744 & 0.0000 \\
\hline November & 0 & 0 & 720 & 0.0000 \\
\hline December & 0 & 0 & 744 & 0.0000 \\
\hline Total number of failures per year & 0 & 0 & 8784 & \\
\hline
\end{tabular}

Table 8 Summary of Outage Frequency and Duration on Outgoing Feeders

\begin{tabular}{|l|c|c|c|c|}
\hline Month & No. of Outages & Outage Time (Hours) & Total Hours & Failure Rate( $\boldsymbol{\lambda})$ \\
\hline January & 2 & 26 & 744 & 0.0027 \\
\hline February & 3 & 10 & 696 & 0.0043 \\
\hline March & 4 & 14 & 744 & 0.0054 \\
\hline April & 2 & 10 & 720 & 0.0027 \\
\hline May & 4 & 12 & 744 & 0.0054 \\
\hline June & 4 & 2 & 720 & 0.0056 \\
\hline July & 3 & 4 & 744 & 0.0040 \\
\hline August & 6 & 5 & 744 & 0.0081 \\
\hline
\end{tabular}




\begin{tabular}{|l|c|c|c|c|}
\hline September & 2 & 2 & 720 & 0.0027 \\
\hline October & 1 & 1 & 744 & 0.0013 \\
\hline November & 3 & 1 & 720 & 0.0042 \\
\hline December & 1 & 1 & 744 & 0.0013 \\
\hline Total number of failures per year & 35 & 88 & 8784 & \\
\hline
\end{tabular}

Table 9 Summary of Outage Frequency and Duration on over current relays

\begin{tabular}{|l|c|c|c|c|}
\hline Month & No. of Outages & Outage Time (Hours) & Total Hours & Failure Rate $(\boldsymbol{\lambda})$ \\
\hline January & 1 & 1 & 744 & 0.0013 \\
\hline February & 0 & 0 & 696 & 0.0000 \\
\hline March & 0 & 0 & 744 & 0.0000 \\
\hline April & 0 & 0 & 720 & 0.0000 \\
\hline May & 0 & 0 & 744 & 0.0000 \\
\hline June & 1 & 2 & 720 & 0.0014 \\
\hline July & 1 & 1 & 744 & 0.0013 \\
\hline August & 0 & 0 & 744 & 0.0000 \\
\hline September & 0 & 0 & 720 & 0.0000 \\
\hline October & 0 & 0 & 744 & 0.0000 \\
\hline November & 0 & 0 & 720 & 0.0000 \\
\hline December & 0 & 0 & 744 & 0.0000 \\
\hline Total number of failures per year & 3 & 4 & & \\
\hline
\end{tabular}

Table 10 Summary of Outage Frequency and Duration on Earth fault relay

\begin{tabular}{|l|c|c|c|c|}
\hline Month & No. of Outages & Outage Time (Hours) & Total Hours & Failure Rate $(\boldsymbol{\lambda})$ \\
\hline January & 0 & 0 & 744 & 0.0000 \\
\hline February & 0 & 0 & 696 & 0.0000 \\
\hline March & 0 & 0 & 744 & 0.0000 \\
\hline April & 1 & 3 & 720 & 0.0013 \\
\hline May & 0 & 0 & 744 & 0.0000 \\
\hline June & 0 & 0 & 720 & 0.0000 \\
\hline July & 0 & 0 & 744 & 0.0000 \\
\hline August & 0 & 0 & 744 & 0.0000 \\
\hline September & 0 & 0 & 720 & 0.0000 \\
\hline October & 0 & 0 & 744 & 0.0000 \\
\hline November & 0 & 0 & 720 & 0.0000 \\
\hline December & 0 & 0 & 744 & 0.0000 \\
\hline Total number of failures per year & & 3 & 8784 & \\
\hline
\end{tabular}


Table 11 Summary of Outage Frequency and Duration on Surge Arresters

\begin{tabular}{|l|c|c|c|c|}
\hline Month & No. of Outages & Outage Time (Hours) & Total Hours & Failure Rate ( $\boldsymbol{\lambda}$ ) \\
\hline January & 0 & 0 & 744 & 0.0000 \\
\hline February & 0 & 0 & 696 & 0.0000 \\
\hline March & 0 & 0 & 744 & 0.0000 \\
\hline April & 0 & 0 & 720 & 0.0000 \\
\hline May & 0 & 0 & 744 & 0.0000 \\
\hline June & 0 & 0 & 720 & 0.0000 \\
\hline July & 0 & 0 & 744 & 0.0000 \\
\hline August & 0 & 0 & 744 & 0.0000 \\
\hline September & 0 & 0 & 720 & 0.0000 \\
\hline October & 0 & 0 & 744 & 0.0000 \\
\hline November & 0 & 0 & 720 & 0.0000 \\
\hline December & 0 & 0 & 744 & 0.0000 \\
\hline Total number of failures per year & 0 & 0 & 8784 & \\
\hline
\end{tabular}

Table 12 Basic Reliability Indices on Each Component for the year under review

\begin{tabular}{|l|c|c|c|c|c|c|}
\hline Components name & $\begin{array}{l}\text { No. of the } \\
\text { components }\end{array}$ & $\begin{array}{l}\text { Failure Rate } \\
(\boldsymbol{\lambda}) \mathbf{( y )}\end{array}$ & $\begin{array}{l}\text { Failure Rate } \\
\text { (f/yr) ( } \boldsymbol{\lambda})\end{array}$ & $\begin{array}{l}\text { No. } \begin{array}{c}\text { of } \\
\text { Failures }\end{array} \\
\begin{array}{l}\text { Average Outage } \\
\text { Time (Hours) }\end{array}\end{array} \begin{array}{l}\text { Outages } \\
\text { time (hour) }\end{array}$ \\
\hline Transformer & 30 & 0.0699 & 0.0059 & 52 & 27.67 & 232 \\
\hline Switch gear & 37 & 0.0537 & 0.0044 & 39 & 5.583 & 1.75 \\
\hline $\begin{array}{l}\text { Supply } \\
\text { Incoming) }\end{array}$ & 20 & 0.0138 & 0.0011 & 10 & 21 \\
\hline Bus bars & 3 & 0.0108 & 0.6667 & 8 & 2.167 & 26 \\
\hline Circuit Breakers & 5 & 0.008 & 0.0007 & 6 & 3.000 & 36 \\
\hline Fuses & 57 & 0.0985 & 0.0082 & 72 & 5.417 & 65 \\
\hline Switches & 5 & 0.0162 & 0.0000 & 0 & 0.000 & 0 \\
\hline Outgoing feeder & 40 & 0.0477 & 0.0039 & 35 & 7.333 & 88 \\
\hline Over current relay & 2 & 0.004 & 0.0003 & 3 & 0.333 & 4 \\
\hline Earth fault relay & 1 & 0.0013 & 0.0001 & 1 & 0.250 & 3 \\
\hline Surge Arrester & 0 & 0.000 & 0.0000 & 0 & 0.000 & 0 \\
\hline
\end{tabular}




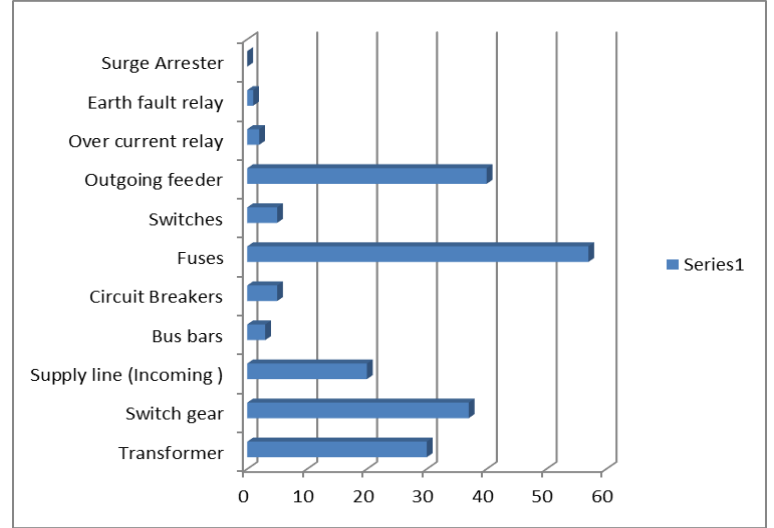

Figure 1 Bar Chart representing the Number of the Components

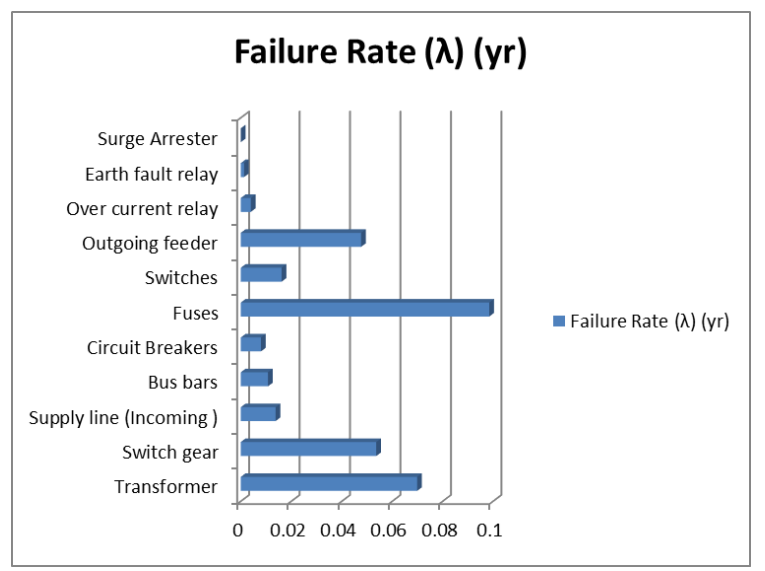

Figure 3 Bar Chart representing the Failure Rate of Each Component

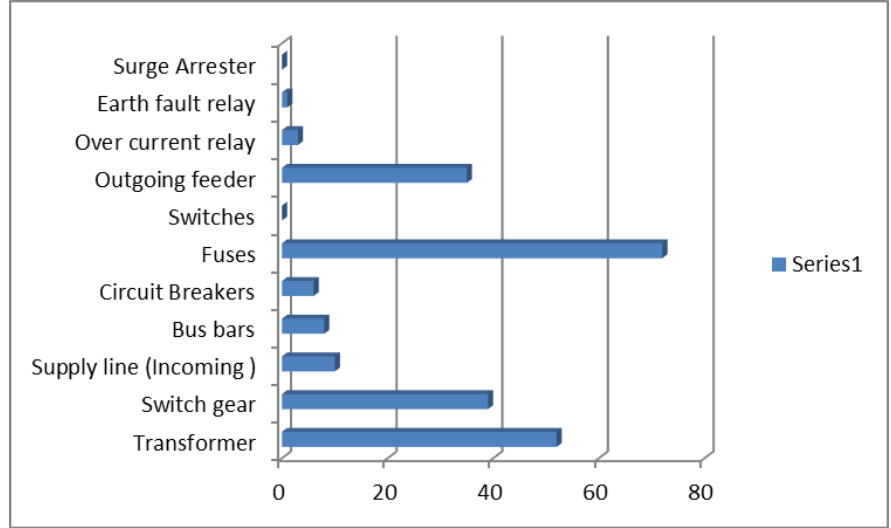

Figure 2 Bar Chart representing the Number of failures that occurred on Component

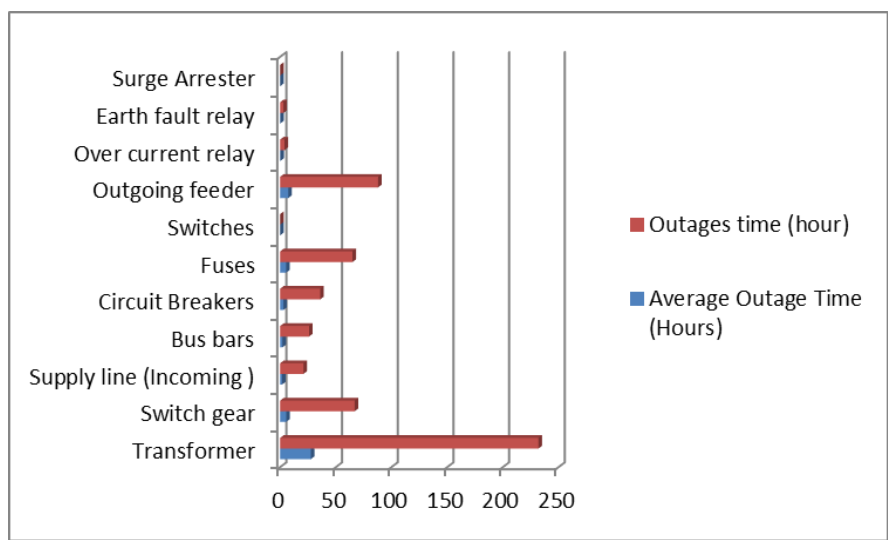

Figure 4 Bar chart representing the Average Outage Time (Hours) and outages time (hour)

\section{Conclusion}

Evaluation of reliability of power system distribution components was carried out using Sagamu as a case study, since power supply is very cogent to the development of a nation economy.

Power outages data that were occasioned as a result of failure on each of these components such as Switch gears, Supply line $(11 \mathrm{Kv})$, Busbar, circuit breakers, Fuses, Switches, Outgoings feeders, Over current relays, Earth fault relays, Surge arresters and transformers e.t.c. were collected from the distribution of Ibadan Electricity Distribution company, Sagamu Substation Zone, Ogun State and were typified in Table 1-11. The reliability indices were evaluated utilizing mathematical and statistical solutions such as the failure rate, Average outages time (hours) and outages time hours were calculated as some of basic reliability indices and were illustrated in Table 12 and some of these failures were also represented in bar charts with fuses has the highest failure followed by transformers and the least was surge arresters. The results were discussed and deduced so as to identify the component contributing most to unavailability and interruption of the system and also revealed the overall reliability of the substation and how this affected the consumers that were connected to the substation the result of the analysis illustrated that fuses failures contributed the highest power outages in the substation followed by the transformers and the switch gears. From the analysis carried out, it has been demonstrated that the frequency of outages affects system's reliability but the outage duration has more impacts on the system availability and reliability. The conclusion from this study demonstrated that it is advantageous to base the evaluation of reliability of power system distribution components decisions on tested, processed, investigated and analyzed outages data.This study could be used in planning of power system, assets management and extension and out rightly improve power supply and the components must be well maintained to prevent unplanned interruptions, concerted efforts should be put in place to see that when there is a component outage, the time duration is reduced in order to obtain more stable and reliable power supply and lastly suitable and constant inspection and maintenance of components by the Utility must be put in place to improve reliability of the substation. 


\section{Compliance with ethical standards}

\section{Acknowledgments}

I would like to thank the Management of Ibadan Electricity Distribution Company for their support on the project and I also appreciate the contribution of my coauthor.

\section{Disclosure of conflict of interest}

No potential conflict of interest was reported by the authors.

\section{References}

[1] Olajuyin EA, Olubakinde E, Adetunmbi AO. Factors affecting Power Supply in Nigeria and The Way forward, International Journal of Electrical Engineering and Ethics. July August 2019; 2(1).

[2] Akintola AA. Reliability evaluation of secondary distribution system in Nigeria: a case study of Ayetoro 1 substation, Aguda, Lagos state, M.Eng. Dissertation, Covenant University, Ota. 2017.

[3] Hui HG, Syyi S, Nur IH, Sulaiman bin M, Chin Wan L, Qing Shi C, Kai Chen G. Types of Circuit Breaker and its Application in Substation Protection, Indonesian Journal of Electrical Engineering and Computer Science. 2017; 8(1): 213- 220.

[4] Marco Antônio Ferreira Boaski, Caio dos Santos, Mauricio Sperandio, Daniel Pinheiro Bernardon, Maicon Jaderson Ramos and Daniel Sperb Porto. 2017.

[5] Allan RN, Billinton R, Shaidehpour SM, Singh C. Bibliography on the Application of Probability methods in power system Reliability Evaluation.IEEE Transactions on power systems. November 1988; 3(4).

[6] Onwualu AP, Oluka SI, Offfiong A. Principle of Engineering Project Management.SNAAP Press Ltd, Enugu. 2002.

[7] Allan RN, Billinton R, Lee SH. Bibliography on the Application of probability methods in power system reliability Evaluation, IEEE Transactions on power Apparatus and systems. 1984; 103(2).

[8] Adefarati T, Bansal R.C. Reliability and economic assessment of a microgrid power system with the integration of renewable energy resources, Applied Energy journal homepage. 2017; 911-933.

[9] Sultana, Beenish MW, Mustafa U, Sultana, Abdul Rauf Bhatti. Review on Reliability Improvement and Power loss Reduction in Distribution System via Network Reconfiguration. Renewable and Sustainable Energy Reviews. 2016; 66: 297-310.

[10] Olajuyin EA, Akinyede JA, Akinyede T. Evaluation of reliability of protective devices in power distribution network, Journal of Emerging Trends in Engineering and Applied Sciences (JETEAS). 2021; 12(1): 13-18.

[11] Amuta E, Adejumobi IA, Wara ST, Abiala IO. A Critical Analysis of the Reliability of Power Holding Company of Nigeria Protection Schemes, International Journal of Engineering and Technical Research (IJETR). 2321-0869, 25, 369-372.

[12] Awale, Kabindra, Nava Raj Karki. Reliability Assessment of Standalone Hybrid Energy System for Remote Telecom Tower. 2015; 27-37.

[13] Alavi, Omid, Abbas Hooshmand Viki, Mohammad Tavakoli Bina, and Mohsen Akbari. Reliability Assessment of a Stand-Alone Wind-Hydrogen Energy Conversion System Based on Thermal Analysis." International Journal of Hydrogen Energy. 2017; 42(22): 14968-14979.

[14] Venkatesan, Latha, S Shanmugavel, and Chandrasekaran Subramaniam. A Survey on Modeling and Enhancing Reliability of Wireless Sensor Network." Wireless Sensor Network. 2013; 41-51. 